\title{
A Relapsing Immune Thrombocytopenia Case in a Patient Following COVID-19 Vaccination
}

\author{
Burcin Meryem Atak Tel ${ }^{1, \odot}$ Gizem Kahveci ${ }^{1, \odot} \quad$ Tuba Taslamacioglu Duman ${ }^{1, \odot ~ O ̈ z g e ~ K u r t k u l a g i 1, \odot ~}$ \\ Satilmis Bilgin ${ }^{1, \odot}$ Hilal Senturk ${ }^{1, \odot}$ Havva Akin ${ }^{1, \odot}$ Gulali Aktas ${ }^{1, \odot}$ \\ ${ }^{1}$ Department of Internal Medicine, Abant Izzet Baysal University \\ Hospital, Bolu, Turkey

\begin{abstract}
Address for correspondence Burcin Meryem Atak Tel, MD, Department of Internal Medicine, Abant Izzet Baysal University Hospital, 14200 Golkoy, Bolu, Turkey (e-mail: burcinatak@hotmail.com).
\end{abstract}

J Health Allied Sci NU 2022;12:96-97.

\begin{abstract}
Keywords

- COVID-19

- immune thrombocytopenia

- inactivated viral vaccine

There are several vaccines developed against COVID-19 infection. Inactivated viral vaccines are usually well tolerated. We aimed to present a relapsing immune thrombocytopenia case following inactive COVID-19 vaccine. Here we report a case of relapsing immune thrombocytopenia following inactivated viral vaccine against COVID-19 in a 60-year-old woman with a history of immune thrombocytopenia. The patient responded well to dexamethasone treatment and was discharged from the hospital with full recovery. We suggest that physicians seek the history of a recent inactivate COVID-19 vaccine shot in patients with immune thrombocytopenia.
\end{abstract}

\section{Introduction}

The ongoing COVID-19 pandemic caused by severe acute respiratory syndrome coronavirus 2 (SARS-CoV-2) has led to high morbidity and mortality worldwide. So many people, especially the elderly and those who have comorbidities, needed an affective, quick treatment for COVID- 19. Healthcare workers, older people (aged $>60$ years), and people who have comorbidities are at particularly high risk ${ }^{1}$ for COVID-19. This has led to quick action in the development of potential vaccines against the disease. Ever since the COVID-19 outbreak began, researchers have been trying to develop vaccines for it, with more than 198 vaccines currently in preclinical or clinical development.

Vaccines against viral pathogens include attenuated live virus, whole inactivated virus, protein subunit, recombinant peptides, replicating or nonreplicating viral vector, and nucleic acid vaccines. Inactivated virus COVID-19 vaccine is being used in large community in our country. Inactivated virus vaccines contain inactivated dead virus and induce strong antibody response; however, they require large quantities of the virus. Another possible disadvantage of these vaccines could be that they may induce autoimmunity in rare cases. $^{2}$

In the present case, we aimed to report a relapsed immune thrombocytopenia case following vaccination with an inactivated SARS-CoV-2 vaccine.

\section{Case Report}

A 60-year-old woman was presented to the emergency department of our institution with the complaints of red eye, gingival bleeding, and rashes on abdominal skin and on the legs since two days before hospital admission. She had received the vaccine shot against COVID-19 infection 6 days before admission, that is, for days before her complaints developed. She had been diagnosed with immune thrombocytopenia 4 months ago and responded well to the published online July 23, 2021
DOI https://doi.org/

$10.1055 / \mathrm{s}-0041-1731915$

ISSN 2582-4287 (c) 2021. Nitte (Deemed to be University).

This is an open access article published by Thieme under the terms of the Creative Commons Attribution-NonDerivative-NonCommercial-License, permitting copying and reproduction so long as the original work is given appropriate credit. Contents may not be used for commercial purposes, or adapted, remixed, transformed or built upon. (https://creativecommons.org/licenses/by-nc-nd/4.0/).

Thieme Medical and Scientific Publishers Pvt. Ltd. A-12, 2nd Floor, Sector 2, Noida-201301 UP, India 
corticosteroid treatment. She had been clinically followed-up without any medication for immune thrombocytopenia. Her medical history also includes hypertension for 20 years and her blood pressure measurements are well controlled with antihypertensive regimen (amlodipine $5 \mathrm{mg} /$ day).

On physical examination, her vital signs were normal (body temperature was $36^{\circ} \mathrm{C}$ systolic and diastolic blood pressures were $120 \mathrm{~mm} \mathrm{Hg}$ and $75 \mathrm{~mm} \mathrm{Hg}$, respectively. Heart rate was 82 beats per minute; respiratory rate was 15 per minute. Scleral hemorrhage was noted in both her eyes. Oral mucosa contained several hemorrhagic bullae and gingival hemorrhage was detected. Petechial and purpuric rashes were revealed on her abdominal skin and both legs. Rest of the physical examination was unremarkable.

Hemogram test revealed that platelet count of the patient was as low as $2,000 / \mathrm{mm}^{3}$. Peripheral blood smear examination revealed findings which were consistent with the platelet count in the hemogram. After receiving corticosteroid treatment for immune thrombocytopenia 4 months ago, her platelet count had reached $278,000 / \mathrm{mm}^{3}$; therefore, cessation of corticosteroid treatment was considered by her hematologist. A recurrent immune thrombocytopenia episode due to recent COVID-19 vaccination was considered according to the history, and clinical and laboratory findings.

Intracranial hemorrhage and other pathologies were ruled out by cranial computerized tomography; $40 \mathrm{mg} /$ day of dexamethasone treatment initiated. One unit of pooled thrombocyte suspension was given intravenously. On the fourth day of the treatment, her platelet count reached $132,000 / \mathrm{mm}^{3}$. Peripheral blood smear at the same time revealed $\sim 150,000 / \mathrm{mm}^{3}$ platelets. Her complaints dissolved. She was discharged from the hospital with full recovery and advised to visit her hematologist for control and follow-up.

\section{Discussion}

We presented an unusual recurrent immune thrombocytopenia case in a woman who received vaccine shot against the novel coronavirus disease. To the best of our knowledge, this is the first report in literature that observed recurrent immune thrombocytopenia after COVID-19 vaccination.

Immune thrombocytopenia is characterized with accelerated platelet destruction due to autoimmunity, resulting in a decrease in the lifespan of the thrombocytes. ${ }^{3}$ Despite the underlying etiology of the immune thrombocytopenia being usually unclear, lymphoid disorders (i.e., lymphoma, chronic lymphoblastic leukemia), infectious diseases (i.e., hepatitis B, hepatitis C), and connective tissue disorders (i.e., systemic lupus erythematosus) may trigger the pathologic mechanisms which lead to immune destruction of the platelets. In addition, immune thrombocytopenia cases have been reported after inactive viral vaccine shots against seasonal flu in literature. ${ }^{4}$ Moreover, other vaccines have been suggested to be responsible of immune thrombocytopenia in various cases. $^{5-7}$ Therefore, we think that recurrence of the immune thrombocytopenia in the present case might have been triggered by the recent shot of inactivated COVID-19 viral vaccine.

Findings in physical examination in patients with immune thrombocytopenia include bleeding from mucous membranes and skin. Therefore, petechiae, purpuric rashes, gingival bleeding, and hemorrhagic bullae may manifest in these patients. ${ }^{4}$ In accordance with literature data, the patient in the present case was suffering from gingival hemorrhage and skin rashes.

The only pathological finding in hemogram test in patients with immune thrombocytopenia is usually isolated thrombocytopenia. Similarly, peripheral blood smear reveals nothing more other than a low platelet count. ${ }^{4}$ The only positive laboratory finding in hemogram and peripheral blood smear of the present case was low platelet count, which was consistent with medical literature.

In conclusion, we suggest that inactivated vaccines against COVID-19 infection could trigger immunity against platelets and may lead to recurrence of immune thrombocytopenia in these patients. Physicians should be aware of this condition and seek the history of recent inactivated COVID-19 vaccine shots in patients with immune thrombocytopenia.

\section{Authors' Contributions}

B.M.A.T., S.B., G.K., O.K., and G.A. performed literature review; B.M.A.T., O.K., G.A., and G.K. managed the case; H.S., H.A., and T.T.D. wrote the first draft; and G.A., H.A., H.S., S.B., and T.T.D. performed critical review of the article., All authors approved the final version of the manuscript.

\section{Conflict of Interest}

None declared.

\section{References}

1 Flaxman S, Mishra S, Gandy A, et al. Imperial College COVID-19 Response Team. Estimating the effects of non-pharmaceutical interventions on COVID-19 in Europe. Nature 2020;584(7820):257-261

2 Aktas G, Altinordu R, Mercan Z, Savli H. Immune thrombocytopenia; following seasonal flu vaccine and nonsteroidal anti-inflamatory drug use. Prof Med J 2016;23:630-633

3 Woods VL Jr, Oh EH, Mason D, McMillan R. Autoantibodies against the platelet glycoprotein IIb/IIIa complex in patients with chronic ITP. Blood 1984;63(2):368-375

4 Fogarty P, Minichiello T, Disorders of hemostasis, thrombosis, and antithrombotic therapy. In: Papadakis MA, McPhee SJ, eds. Current Medical Diagnosis and Treatment. 54th ed. New York, NY: McGraw Hill Lange Publication; 2015:536-561

5 Peltola $\mathrm{H}$, Heinonen OP, Valle $\mathrm{M}$, et al. The elimination of indigenous measles, mumps, and rubella from Finland by a 12-year, two-dose vaccination program. $\mathrm{N}$ Engl J Med 1994;331(21):1397-1402

6 Meyboom RH, Fucik H, Edwards IR. Thrombocytopenia reported in association with hepatitis B and A vaccines. Lancet 1995;345(8965):1638

7 Schattner A. Consequence or coincidence? The occurrence, pathogenesis and significance of autoimmune manifestations after viral vaccines. Vaccine 2005;23(30):3876-3886 